\title{
GESTÃO DE CONTEÚDO DE ÓDIO NO FACEBOOK: UM ESTUDO SOBRE HATERS, TROLLS E NAYSAYERS
}

\author{
Luiz Rogério Lopes Silva \\ Universidade Federal do Paraná \\ luizlopescomunicacao@gmail.com \\ Rodrigo Eduardo Botelho-Francisco \\ Universidade Federal do Paraná \\ robotelho@gmail.com
}

\begin{abstract}
Resumo
$\mathrm{O}$ artigo tem o objetivo de identificar e compreender os tipos de interagentes-odiadores, sejam haters, trolls ou naysayers, presentes nas fanpages de políticos brasileiros que defendem pautas conservadoras e observar a relação homofílica ou heterofílica entre os atores envolvidos na produção e disseminação do cyberhate. A metodologia consiste na Análise de Conteúdo de 3.550 comentários contendo discurso de ódio recuperados nas páginas oficiais no Facebook dos parlamentares Jair Bolsonaro, Marco Feliciano e Rogério Peninha. Todos os três deputados foram protagonistas de declarações de intolerância religiosa, racistas, sexistas e homofóbicas, tanto em suas redes sociais quanto na mídia tradicional. Os resultados revelaram uma preponderância de interagentes-haters e alta relação entre o conteúdo da postagem e os comentários de ódio. Observou-se também que a relação homofílica dos interagentes com os respectivos parlamentares prevaleceu sobre as interações heterofílicas e o contra-ódio. O estudo aponta para a necessidade de um aprimoramento na gestão deste tipo de conteúdo, principalmente na representação e recuperação de termos e expressões odientas.
\end{abstract}

Palavras-chave: Gestão de Conteúdo. Discurso de Ódio. Haters. Trolls. Naysayers.

\section{HATE CONTENT MANAGEMENT IN FACEBOOK: A STUDY ABOUT HATERS, TROLLS AND NAYSAYERS}

\begin{abstract}
The article aims to identify and understand the types of interacting-haters, whether haters, trolls or naysayers, present in fanpages of Brazilian politicians who defend conservative agendas and observe the homophilic or heterophilic relationship between the actors involved in the production and dissemination of cyberhate . The methodology consists of Content Analysis of 3,550 comments containing hate speech retrieved from the official Facebook pages of parliamentarians Jair Bolsonaro, Marco Feliciano and Rogério Peninha. All three deputies were protagonists of declarations of religious intolerance, racist, sexist and homophobic, both on their social networks and in the traditional media. The results revealed a preponderance of interacting-haters and a high relationship between the content of the post and the hateful comments. It was also observed that the homophilic relationship of the interactants with the respective parliamentarians prevailed over heterophilic interactions and counter-hatred. The study points to the need for an improvement in the management of this type of content, mainly in the representation and recovery of odious terms and expressions.
\end{abstract}

Keywords: Content Management. Hate Speech. Haters. Trolls. Naysayers.

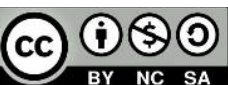

Esta obra está licenciada sob uma Licença Creative Commons (Attribution 4.0 International) P2P \& INOVAÇÃO, Rio de Janeiro, v. 6, n. 2, Ed. Especial, p. 38-56, 2020. 


\section{INTRODUÇÃO}

Em 28 de agosto de 2014, numa transmissão de uma partida de futebol pela Copa do Brasil, ao vivo, a câmera da TV Globo flagrou uma torcedora chamando o goleiro do time rival de "macaco"; quatro anos depois, torcedores brasileiros postam vídeo ofendendo uma repórter na Copa do Mundo da Rússia ${ }^{2}$. Os dois episódios, além de envolverem uma paixão nacional o futebol -, são manifestações explícitas de discurso de ódio racista e sexista, respectivamente. Todos os torcedores envolvidos nos relatos afirmam não terem tido a intenção de intimidar ou ofender as vítimas, mas ambas as atitudes foram classificadas como um ato violento e de humilhação à dignidade da pessoa humana.

Estes exemplos refletem, em alguma medida, como a sociedade tem reagido a casos de intolerância, hostilidade e violência e quão difícil tem sido a identificação do que seria ou não “discurso de ódio". Há quem defenda as vítimas e punições aos culpados; há quem entenda como demasiadas as intervenções e sanções judiciais e sociais. Neste contexto, o desafio de reconhecer o discurso de ódio sem censurar pontos de vista legítimos é grande, sobretudo em contextos digitais, onde os atores, conscientizados ou não (ISASI; JUANATEY, 2016) sentemse confortáveis em manifestar o preconceito, a discriminação e a violência.

O discurso de ódio online, também conhecido como cyberhate ou ódio cibernético, apresenta-se em diferentes formatos, em diferentes plataformas, e é possível de ser visualizado em vários contextos (GAGLIARDONE et al., 2015). Entre as características que diferem o cyberhate dos modos convencionais de discurso de ódio estão a permanência e itinerância do fenômeno (GAGLIARDONE et al., 2015), que permitem que o conteúdo seja reproduzido e visualizado em vários contextos, possibilitando inclusive que ressurja em outro lugar, mesmo que seja removido.

Estudos mais recentes atribuem ao anonimato e à invisibilidade as razões para as pessoas externalizarem o discurso de ódio online (COHEN-ALMAGOR, 2017; CITRON, 2014; HUGHEY; DANIELS, 2013; RECUERO, 2009). Aspectos como o sentimento de pertencimento ao grupo de ódio (CITRON, 2014) e a instantaneidade do discurso proferido, comentado e replicado (BROWN, 2018) também são vistos como fomentadores do comportamento incivil online. Há trabalhos que identificam a reação instantânea (o contraódio) como um aspecto preocupante nos espaços digitais. Neste caso, os interagentes que

\footnotetext{
${ }^{1}$ Ver mais em: http://g1.globo.com/rs/rio-grande-do-sul/noticia/2014/09/patricia-moreira-quebra-silencio-e-daentrevista-sobre-caso-de-racismo.html - Acessado em 05 de julho de 2019.

${ }^{2}$ Ver mais em: https://g1.globo.com/mundo/noticia/videos-machistas-de-torcedores-na-russia-se-espalham-pelaweb-e-causam-revolta.ghtml - Acessado em 05 de julho de 2019.
} 
sofrem agressão (ROSNER; KRAMER, 2016) têm mais probabilidade de responder de forma agressiva, criando, assim, um círculo vicioso de incivilidade online.

No que tange este artigo, o fenômeno é analisado em suas manifestações em Redes Sociais Digitais (RSD), mais especificamente no Facebook, com foco na relação entre os atores ali presentes, aqui chamados de interagentes. A pergunta que norteia este trabalho é: Qual o tipo de interagente-odiador é mais recorrente no Facebook e qual a relação entre os atores envolvidos na produção e disseminação de conteúdo de ódio?

O objetivo é identificar e compreender os tipos de interagentes-odiadores presentes nas fanpages de políticos brasileiros que defendem pautas conservadoras, compreender a ligação entre os atores e verificar se existe relação entre os comentários dos seguidores e a publicação dos parlamentares. Para tanto, foram analisadas as interações nas páginas oficiais dos deputados federais Jair Bolsonaro - à época de seu sexto e sétimo mandato, entre os anos de 2013 e 2016, - e dos deputados Marco Feliciano e Rogério Mendonça Peninha no mesmo período.

A escolha dos parlamentares levou em consideração o fato dos três terem protagonizado discursos e publicações de ódio contra minorias historicamente marginalizadas e o expressivo número de seguidores dos parlamentares no Facebook. Em relação ao segundo aspecto, cabe salientar que durante o processo de extração dos dados cada um dos deputados ultrapassava o número de 500 mil seguidores, e em suas bancadas de atuação (evangélica, agropecuária e de segurança pública), ocupavam a primeira colocação em número de seguidores se comparado aos demais colegas parlamentares.

No decorrer do artigo serão explanados os conceitos de haters, trolls e naysayers, levando em consideração, de maneira geral, as diferentes formas em que cada interagente manifesta sua intolerância. Os haters de forma mais agressiva e direta, os trolls através do humor e da perturbação e os naysayers pela oposição e indiferença. Também serão abordados os conceitos de Homofilia e Heterofilia para identificar a relação entre as publicações dos deputados e os comentários de ódio, sendo que a relação homofílica representa o apoio as pautas de ódio levantadas pelo parlamentar e a heterofílica estaria ligada ao contra-ódio e as reações também intolerantes de outros interagentes para com os parlamentares, suas bandeiras e seus apoiadores.

O resultado deste trabalho é apresentado em quatro partes: (a) discurso de ódio online; (b) os tipos de interagente-odiador; (c) o discurso de ódio homofílico e heterofílico; e (d) método e analise dos comentários odientos. $\mathrm{O}$ trabalho tem caráter interdisciplinar e é parte de um projeto que visa representar e recuperar o discurso de ódio online brasileiro por meio de um vocabulário controlado com termos e expressões de ódio sexista, racista, xenofóbico, 
homofóbico, aporofóbico, etário, intolerância religiosa, político-partidário, por aparência e contra pessoas com necessidades especiais.

\section{DISCURSO DE ÓDIO ONLINE}

O discurso de ódio online é um fenômeno complexo, multifacetado e envolve diferentes atores. A literatura tem tratado o discurso de ódio como um fenômeno social que provoca sérios danos, individual e coletivamente, diretos e indiretos, à saúde das relações (COHENALMAGOR, 2017; CITRON, 2014; HUGHEY; DANIELS, 2013). O tema é bastante vinculado à liberdade de expressão e à proteção da dignidade da pessoa humana, o que suscita um conflito sobre os limites entre estes direitos fundamentais. Frente a isto, uma série de áreas do conhecimento, incluindo o Direito, Comunicação, Ciência Política e Ciência da Computação, tem se esforçado para compreender o fenômeno e encontrar possíveis alternativas para diminuir sua durabilidade e escalonamento.

Além disso, empresas de tecnologia, governos, organizações civis e a própria academia reconhecem a Internet, sobretudo as Redes Sociais Digitais, como um ambiente propenso a expressão do ódio, constituindo uma formulação do espaço público capaz de replicar e radicalizar os conflitos da realidade social (ROST; STAHEL; FREY, 2016). Nestes espaços, por sua vez, os interagentes encontram novas oportunidades para o chamado cyberbullying (KOWALSKI et al., 2012) e ódio cibernético (JAISHANKAR, 2008).

Entende-se por cyberbullying "qualquer comportamento realizado através de mídia eletrônica por indivíduos ou grupos de indivíduos que repetidamente comuniquem mensagens hostis ou agressivas destinadas a causar dano ou desconforto aos outros" (TOKUNAGA, 2010 , p. 278); e por ódio cibernético (cyberhate) um tipo de cyberbullying que geralmente usa de abuso verbal, humilhação, desprezo e falsas suposições sobre a cultura e práticas de um indivíduo ou grupo de características protegidas, assumindo as formas de ameaças, discriminação, intimidação, marginalização, alteridades e narrativas desumanas (BLAYA, 2018). Cabe aqui salientar que, para este artigo, discurso de ódio online, cyberhate e ódio cibernético são usados como sinônimos.

As empresas de redes sociais têm investido em alternativas que promovam um ambiente seguro para livre expressão de seus interagentes, mas encontram dificuldades operacionais diante do desafio de trabalhar com grande fluxo de dados, administrar crescente volume de denúncias e atuar simultaneamente em diversas jurisdições (BLAYA, 2018). A preocupação com a replicabilidade, alcance e os danos deste tipo de conteúdo impróprio, bem como o uso 
que os interagentes fazem ao receber esse tipo de informação impulsionou mudanças nas interfaces das plataformas, nas tecnologias e modelos de moderação e nos projetos de educação à tolerância (BLAYA, 2018; SILVA et. al., 2019).

Por outro lado, a obscuridade de muitas plataformas em relação a práticas e políticas de moderação prejudica a otimização de iniciativas que venham a amenizar os danos de conteúdo impróprio. Para Roberts (2019, p. 48-49), "as empresas têm o receio de que a divulgação completa da natureza de suas políticas leve interagentes inescrupulosos a quebrar as regras ou potencialmente dê vantagem aos concorrentes, revelando práticas ou processos considerados secretos".

Para além da discussão e dos desafios da moderação de conteúdo de ódio, faz-se necessário compreender a dinâmica do fenômeno e os atores responsáveis pela sua construção e disseminação. Os próximos tópicos apresentam três tipos de interagente-odiador e explanam a relação de homofilia e heterofílica possíveis nas performances das pessoas nas redes sociais. A partir deste referencial foram construídas as categorias de análise deste trabalho.

\section{OS TIPOS DE INTERAGENTE-ODIADOR}

A propagação do discurso de ódio online envolve múltiplos atores, conscientizados ou não (ISASI; JUANATEY, 2016), individual ou coletivamente, responsáveis por produzir, legitimar e reproduzir o conteúdo odiento até a exaustão. Organizadas em grupos ou de forma particular, as pessoas têm utilizado a Internet para disseminar conteúdo de ódio racial, xenofobia, antissemitismo, nacionalismo agressivo, etnocentrismo, discriminação e hostilidade a minorias.

A ação central dos grupos de ódio consiste no compartilhamento de informações (incorretas ou deturpadas), pontos de vista extremistas e mensagens ideológicas, a fim de recrutar apoiadores e consolidar uma consciência coletiva (COMITÊ DA EUROPA, 2017). Para Klein (2012), o comportamento destes coletivos também busca legitimar a intolerância online por meio do status de "lavagem da informação", ou seja, os formatos e construções da intolerância e do extremismo no espaço digital facilitam a camuflagem e conversão de informação ilegítima em legítima - baseada em ódio - tornando-a rapidamente aceitável.

Klein (2012) alinha o discurso de ódio à (des)informação e compreende o fenômeno como um fluxo de informação valioso aos interesses escusos dos grupos de ódio. Para ele, é por esses espaços online que: 
os grupos de ódio estão entrando na cultura dominante, obtendo legitimidade [...], principalmente pelos mecanismos de busca e interconexão de redes sociais. Esses caminhos convencionais podem involuntariamente levar um buscador de informações online a conteúdos extremistas que [...] já foram projetados para serem usados como educacionais, políticos, científicos e até espirituais por natureza (KLEIN, 2012, p. 431-432)

Individualmente, o interagente-odiador reproduz comportamentos dos quais estaria inibido no convívio social, em sua maioria classificados como trolling ou cyberbullying. Neste caso, o interagente-troll é uma pessoa que encoraja discussões e conflitos na Internet por meio de comentários absurdos, fora do tema ou simplesmente provocando e deturpando a natureza das interações dentro de um grupo ou comunidade online (COMITÊ DA EUROPA, 2017). Em geral, são narcisistas e sádicos, e provocam os outros interagentes por diversão, algumas vezes inconscientes dos danos que podem causar (ISASI; JUANATEY, 2016). O interagente-troll finge ser parte de uma comunidade online com intenções sinceras, enquanto sua "verdadeira intenção" é causar perturbações e/ou provocar ou exacerbar conflitos, usando de um suposto sentido do humor para mostrar sua hostilidade e abusar verbalmente de outros indivíduos e grupos minoritários (HARDAKER, 2010; ISASI; JUANATEY, 2016).

Figura 1: Exemplo de comentário proferido por um troll

aspas bem grande?

Revistinha é a Veja... Será que o Temer toma um par de

Curtir - Responder · $16 \cdot 21$ de abril de 2016 às 11:40

Fonte: Facebook de Jair Bolsonaro

Os interagentes-haters, por sua vez, sempre usam de discurso de violência e agressividade (REBS; ERNST, 2017). O termo vem da expressão americana do hip hop "haters gonna hate" - e remete à pessoa que, se aproveitando da situação de estar em frente a um computador, permite-se livre para odiar. De acordo como Breves e Sampaio (2014), os haters buscam diversão no ódio sem se importarem com a veracidade ou não do que estão falando. Para as autoras, o interante-hater é sempre contra o que o outro diz, sem fundamento algum e com muito ódio. O lema é "odiar por odiar".

Figura 2: Exemplo de comentário proferido por hater

Como macacos: cagam, mijam, cospem, jogam bosta, catam piolho e talvez até batam punheta. Tudo em público. Tão lindo... gente suja. Alguém ensinou a eles que é correto chamar uma pessoa que defende a castração química de estupradores de estuprador... Tinham que ser amestrados também para enfiarem suas cabeças em um balde de bosta, quando essa vontade incontrolável de gritar isso viesse.

Fonte: Facebook de Marco Feliciano 
Em um estudo sobre o ódio à comunidade islâmica, Awan (2016) classifica os haters em cinco categorias: oportunistas, enganadores, fantasistas, produtores e distribuidores. Para o autor, o comportamento oportunista pode ser identificado em incidentes particulares como ataques terroristas, onde o odiador aproveita o acontecido para manifestar seu ódio aos membros da comunidade; já o enganador usa de posts e comentários para criar e intensificar o ódio por meio de acusações falsas; os fantasistas inventam histórias que transitam entre ficção e realidade, apresentando-se de forma intensa e violenta; e os produtores e distribuidores estão diretamente ligados, já que enquanto um produz clima de medo, ódio e hostilidade, o outro distribui e compartilha.

Rebs e Ernst (2017), ao abordar o "excesso" presente no discurso dos haters, identificou três elementos recorrentes: (1) a repetição de palavras pejorativas; (2) a repetição de ideologias; e (3) a repetição de demonstrações de autoridade. Aqui, vale ressaltar que a repetição de palavras pejorativas, sobretudo insultos, xingamentos e ataques ad hominem, são as mais recorrentes nas RDS (COE et al., 2014). Neste contexto, os haters usam de linguagem rude, críticas severas, raiva, muitas vezes reproduzindo o discurso de ódio de outrem, sem análise crítica da informação, numa relação ideológica explícita e extremista.

Outro tipo de interagente-odiador ainda pouco explorado na seara do discurso de ódio e dos comportamentos incivis na Internet é o naysayer (opositor). Ao que parece, este tipo de interagente tem como objetivo controlar o comportamento dos demais interagentes, opondo-se a qualquer um dos argumentos. Ele reage "sempre negativamente a qualquer debate público. Não importa a ideologia ou a questão em debate, sua reação é sempre arbitrária" (SILVA; SAMPAIO, 2018, p. 101). Os chamados "manipuladores" ou "opositores" costumam usar do espaço online para promover suas próprias agendas à despesa dos outros. Eles tentam manter o status quo e se opor a qualquer dos lados da situação (odiador ou vítima).

Figura 3: Exemplo de comentário proferido por Naysayers Seja PT, PSDB, ou qualquer partido que seja só querem saber dos seus interesses a pátria mãe
infelizmente não tem jeito com esses deputados e senadores e juízes do STF não tem mais jeito lamentável em
dizer isso porque falo não morando nos EUA mas sim no Brasil mesmo Fonte: Facebook de Jair Bolsonaro

O conceito de naysayers permanece em construção e vem sendo estudado quanto ao comportamento dos interagentes em relação a marcas e patentes, artistas e celebridades, sobretudo na área de Administração e Marketing. Para este artigo, entendemos como naysayers 
os interagentes que buscam desqualificar qualquer um dos lados - opressores e vítimas de opressão - promovendo um descrédito na dignidade da pessoa humana e/ou uma indiferença contra os grupos/minorias, generalizando ou diminuindo a problemática.

\section{O DISCURSO DE ÓDIO HOMOFÍLICO E HETEROFÍLICO}

O ódio online externalizado em RDS pode ser endossado por semelhantes (o que neste artigo é classificado como homofílico) ou de forma reativa, surgindo como uma reação dos que professam pensamento contrário (heterofílico) ao político administrador da fanpage. Neste sentido, entende-se por homofilia a tendência de os indivíduos estabelecerem ligações mais fortes com pessoas semelhantes em suas características sociais, enquanto que heterofilia é a existência de relações entre os membros de um grupo, definidos a partir das características atribuíveis comuns, com pessoas de um outro grupo com características diferentes (LOZARES et al., 2013). Heterofilia não se opõe ao conceito de homofilia; é complementar (LOZARES et al., 2013). Trata-se da tendência de manter laços mais estreitos com pessoas que são diferentes.

Para Macpherson et al. (2001, p.416), homofilia "é o principio de que um contato entre pessoas semelhantes ocorre em uma taxa maior do que entre pessoas diferentes", sendo abordada em vários estudos de rede que busca identificar a relação entre os atores (LOZARES et al., 2013). Lazarsfeld e Merton (1954) fazem uma distinção entre homofilia de valores e homofilia de status. A primeira remete à ideia da similaridade nas relações baseadas na partilha de recursos de forma cognitiva nas interpretações, opiniões, valores, normas etc.; já a segunda estaria mais relacionada com semelhanças em recursos econômicos, nível social e educação, proporcionando às pessoas se relacionarem com mais intensidade.

Estudos apontam dois aspectos responsáveis pela homofilia: (a) aspectos individuais como as preferências, cálculos estratégicos e características semelhantes que representam um decréscimo de riscos inesperados e aumentam vantagens práticas (MOUW, 2003); (b) a associação ou referência a um coletivo, incluindo a disponibilidade, a influência ou a partilha de focos e recursos comuns, maior confiança e solidariedade (MOLLICA et al., 2003).

Outra distinção importante é homofilia eletiva e homofilia indutiva (MCPHERSON et al., 2001). A primeira se baseia em critérios de afinidade pessoal em diferentes campos e/ou estratégias intencionais na escolha de relacionamentos. A segunda é baseada em características situacionais, tais como o contexto, a localização, a proximidade geográfica, local de trabalho etc. 
Figura 4: Exemplo de comentário homofílico

preso...

Não esse lixo năo vai parar de matar não é doente é um mostro,um mostro criado por esse governo vagabundo,que nåo mexe nessas leis dos infernos que só protege bandidos...

Tomam vergonha na cara brasileiros!!!

Vote bolsonaro porque bandido bom é bandido morto!!!

Curtir - Responder - 29 de agosto de 2016 às 21:34

Fonte: Facebook de Jair Bolsonaro

Benkler (2006) salienta que a Internet torna muito mais provável que indivíduos com interesses incomuns se encontrem, porque expandem amplamente o conjunto pesquisável de atores com os quais se pode interagir significativamente. Para o autor, a homofilia também pode ocorrer, mas de forma mais indireta. Os indivíduos podem, por exemplo, convergir em torno de uma fonte comum de informações online que é atraente, tendo em conta seus interesses compartilhados e agrupados apenas como uma consequência secundária desse interesse compartilhado.

Figura 5: Exemplo de comentário heterofílico

Psicopata, ele sabe q jamais ganharia p presidente mas ele $n$ quer ser mesmo, o q ele quer é estar mesmo na mídia e sempre ter votos $p$ deputado ou senador , pra que vida melhor? $\mathrm{E}$ fingir $\mathrm{q}$ faz algo , com idéias absurdas e degenerativas , mas tudo passa e isso aí com certeza também passa !!! Curtir - Responder + 27 de setembro de 2016 às 09:24

Fonte: Facebook de Jair Bolsonaro

Pelo exposto, cabe reforçar que para esta pesquisa os comentários que apoiam ou reforçam o posicionamento do parlamentar analisado e o teor de sua publicação incivil serão classificados como discurso de ódio homofílico. As interações consideradas como discurso de ódio heterofílico serão as que fazem oposição a publicação ou a outro comentador também com discurso de ódio.

\section{MÉTODO E ANÁLISE DE COMENTÁRIOS ODIENTOS}

Para analisar o conteúdo de ódio presente nas fanpages do Facebook, como proposto no objetivo deste trabalho, foi feita uma coleta de dados utilizando o aplicativo Netvizz ${ }^{3}$, de forma

\footnotetext{
${ }^{3}$ Netvizz é um software desenvolvido no contexto do DMI - Digital Methods Initiative, por Bernard Rieder. Sua função é coletar diferentes tipos de dados do Facebook, sobretudo de páginas, grupos e eventos. É possível extrair o conteúdo textual das postagens e comentários, e também dados de likes, comentários, compartilhamentos e reações. Vale ressaltar que durante a coleta dos dados desta pesquisa a API do Facebook permitiu a extração por
} 
a recuperar todas as postagens dos deputados e seus respectivos comentários desde 01 de janeiro de 2013 até 31 de dezembro de 2016, contemplando dois mandatos diferentes (pleito 20102014 e 2015-2018). O total coletado nas três páginas foi de 12.630 postagens com 8.730 .909 comentários. Deste número foram selecionados 121.747 comentários em 4.618 postagens que continham uma ou mais palavras-chaves e expressões de ódio conforme dicionário proposto por Silva e Sampaio (2018).

O próximo passo foi determinar uma amostra em multiestágio (PÉLLICO NETTO; BRENA, 1997) que elegeu 3.550 comentários para realização da Análise de Conteúdo (NEUENDORF, 2016). Esta análise, por sua vez, foi pautada num livro de códigos que permitiu uma descrição objetiva e sistemática dos comentários, interpretação e inferências em três categorias: (a) relação do comentário com a postagem; (b) as ligações homofílicas e heterofílicas dos interagentes com o conteúdo da publicação; e, por fim, (c) o tipo de interagente-odiador. A codificação foi realizada por três pesquisadores após testes de fiabilidade tendo como coeficiente de confiabilidade o Kappa de Cohen.

Quadro 1 - Número de posts e comentários extraídos nos anos de 2013-2016 nas páginas oficiais dos deputados

\begin{tabular}{|c|c|c|c|c|c|c|}
\hline Parlamentar & Período & $\begin{array}{l}\mathbf{N}^{\circ} \text { de } \\
\text { curtidas }\end{array}$ & $\begin{array}{l}\text { qtd. de } \\
\text { posts }\end{array}$ & $\begin{array}{l}\text { qtd. de } \\
\text { comentários }\end{array}$ & $\begin{array}{c}\text { qtd. de } \\
\text { interações } \\
\text { com termos } \\
\text { de ódio }\end{array}$ & $\begin{array}{c}\mathrm{N}^{\circ} \text { de } \\
\text { interações } \\
\text { analisadas }\end{array}$ \\
\hline $\begin{array}{l}\text { JAIR } \\
\text { BOLSONARO }\end{array}$ & \multirow{3}{*}{$\begin{array}{c}01 / 06 / 2013 \mathrm{a} \\
31 / 12 / 2016\end{array}$} & 4.193 .759 & 1.548 & 3.819 .909 & \multirow{3}{*}{$\begin{array}{c}\mathbf{1 2 1 . 7 4 7} \\
\text { (78.004 de } \\
\text { Feliciano } \\
38.412 \text { de } \\
\text { Bolsonaro } \\
5.531 \text { de } \\
\text { Peninha) }\end{array}$} & \multirow{3}{*}{$\begin{array}{c}\mathbf{3 . 5 5 0} \\
(1.394 \text { de } \\
\text { Feliciano } \\
1294 \text { de } \\
\text { Bolsonaro } \\
862 \text { de } \\
\text { Peninha) } \\
\end{array}$} \\
\hline $\begin{array}{l}\text { MARCO } \\
\text { FELICIANO }\end{array}$ & & 4.038 .406 & 6.907 & 4.260 .218 & & \\
\hline $\begin{array}{l}\text { ROGÉRIO } \\
\text { PENINHA }\end{array}$ & & 507.801 & 4.175 & 650.782 & & \\
\hline TOTAL & - & - & 12.630 & 8.730 .909 & & \\
\hline
\end{tabular}

FONTE: Os autores (2019).

Os resultados mostram que 2,5\% das interações (196 comentários) não continham discurso odiento apesar de terem uma ou mais palavras-chave/expressões do dicionário proposto. Os dados mostraram que o comportamento dos interagentes nas fanpages responde ao estímulo de ódio das postagens dos parlamentares. A análise dos comentários revelou que a maioria do discurso de ódio, neste caso, foi estimulado pela publicação. As fanpages se

meio do Netvizz, no entanto esta funcionalidade deixou de estar disponível a partir de 2018, quando a plataforma restringiu o acesso aos dados. Por sua vez, o uso dos dados coletados nesta pesquisa respeita a Política de Dados e Termos de Serviço do Facebook à época. 
mostraram incivis e desrespeitosas, sobretudo pelo comportamento incitador de seus administradores.

Dos 3.354 comentários analisados e identificados com discurso de ódio, $72 \%$ tinha ligação direta com o assunto da postagem, 14\% relação parcial e 11,5\% não tinham relação ou não foi possível identificar o conteúdo da publicação, haja vista que o conteúdo extraído pelo Netvizz traz o texto da legenda e a informação se a publicação foi um vídeo, uma fotografia ou uma live (streaming de vídeos), mas não recupera o conteúdo audiovisual.

Grafico 1- Relação do comentário com a postagem

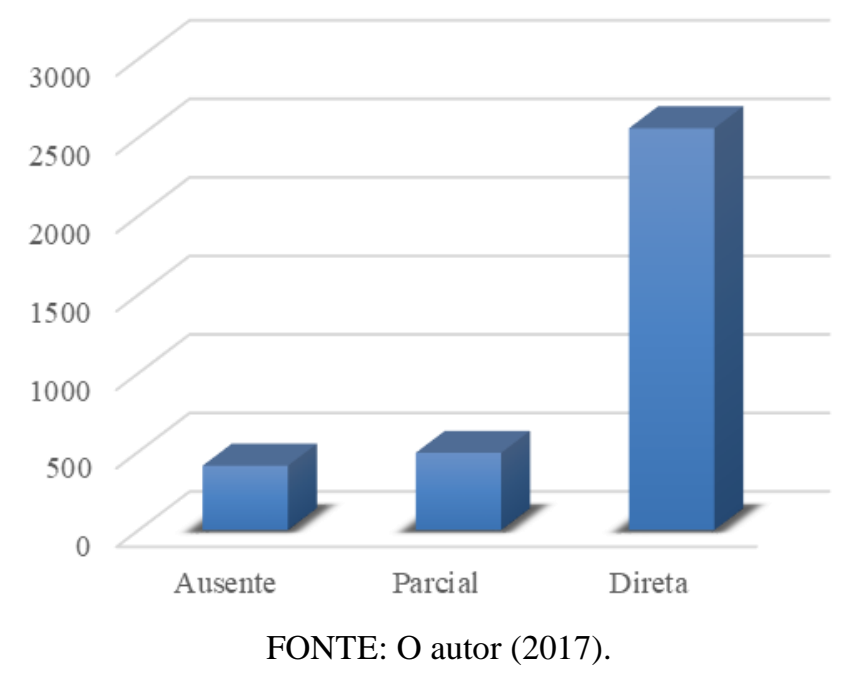

A página oficial de Marco Feliciano apresentou o maior número de ausência de relação do comentário com a postagem (349 comentários de 1394 analisados), o que não significa que a relação não existiu. O parlamentar compartilha muita fotografia, vídeo e outros formatos sem a utilização de nenhuma legenda. Sendo assim, optou-se por classificar como ausente a relação entre comentários e postagem, tendo em vista a limitação em analisar cada publicação em seu link original e assim identificar o verdadeiro teor de seu conteúdo.

Os 492 comentários que tinham relação parcial com a publicação de um dos parlamentares utilizavam da plataforma para atacar outro comentador a partir de sua posição favorável ou contrária a publicação do parlamentar. A troca de ofensas ganhou proporção, afastando-se do assunto do post (a figura 6 ilustra esta dinâmica).

A observância da transmissão homofílica e heterofílica mostrou que o discurso de ódio repercutiu com maior incidência entre os de pensamento comum - os apoiadores dos parlamentares. Dos 3.334 comentários analisados, $77 \%$ eram de discurso de ódio homofílico e $33 \%$ heterofílico. O discurso de ódio incitado pelas publicações recebeu apoio e ressonância. A 
dinâmica dos processos de assimilação, de influência e de imitação social desenhou um cenário de homofilia eletiva (MCPHERSON et al., 2001), ou seja, afinidade pessoal em diferentes campos e/ou estratégias intencionais. Neste caso, o ódio ao Partido dos Trabalhadores, aos oponentes políticos dos parlamentares (sobretudo a presidente Dilma Rousseff e o ex-presidente Lula) e às correntes de esquerda tiveram mais peso e adeptos.

Também foi possível observar uma homofilia plural nas três páginas. As interações aconteceram entre diversos grupos diferentes entre si, mas igualmente apoiadores das figuras públicas e/ou suas agendas eleitorais e políticas. Aspectos como erros ortográficos e gramaticais mostraram, em certa medida, uma discrepância de formação intelectual entre os atores, porém uma união entre os interagentes pautada num discurso de defesa e pertencimento motivado pelo ódio aos que se posicionavam de forma diferente.

Grafico 2 - Transmissão do discurso odiento

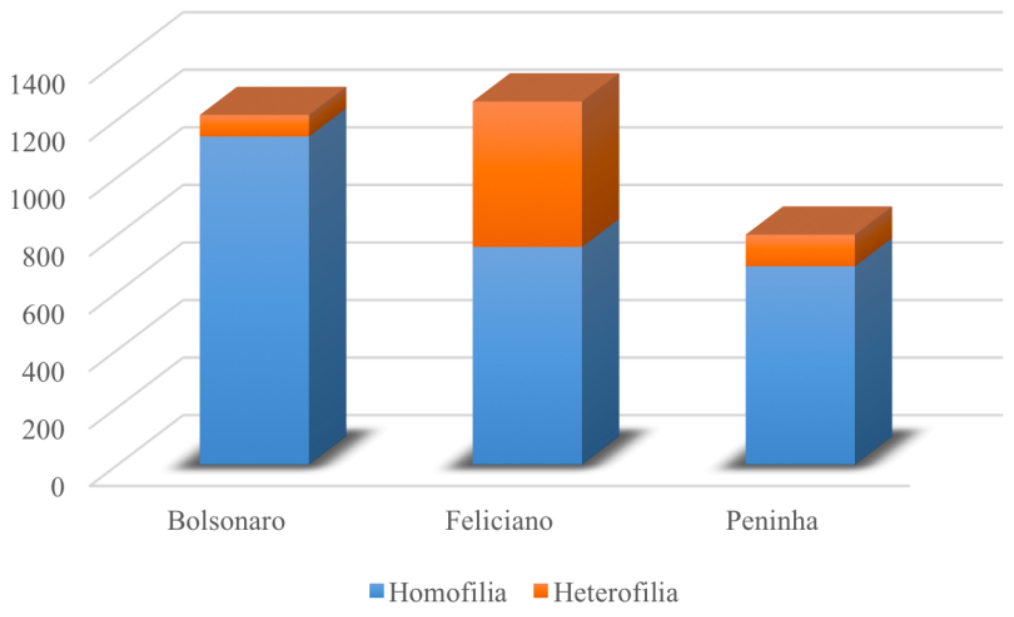

FONTE: O autor (2018)

As interações também sofreram interferência de discursos de ódio heterofílicos. Os ataques eram voltados ao deputado em questão, seus argumentos e a outros seguidoresapoiadores. A página de Feliciano ganha destaque nesse quesito, já que o número de comentários heterofílicos ( 756 comentários homofílicos e 506 heterofílicos) é maior que a soma dos outros dois parlamentares (Bolsonaro: 1140 comentários homofílicos e 75 heterofílicos, Peninha: 689 comentários homofílicos e 110 heterofílicos). A rejeição às publicações do deputado e à sua figura pública é alta, demostrada por um discurso de ódio ad hominen, carregado de insinuações sobre a índole política e religiosa do parlamentar, além de afrontas à sua sexualidade. 
A figura 6 mostra como diferentes atores reagiram a publicação do parlamentar Marco Feliciano. É possível observar que o primeiro comentador ataca o deputado chamando-o de "tosco" e "nojento" e faz uma generalização de que todo pastor é "sujo". Na sequência, outro interagente pede respeito às religiões, enquanto um terceiro responde agressivamente à primeira interagente usando da expressão: "vc merece uma surra de pika! A seco u.u”.

O exemplo ilustra a dinâmica de incivilidade nas redes sociais apresentando as interações de ódio e contra-ódio. Por outro lado, a ausência de informações mais profundas sobre os comentadores advindas de dados sensíveis ${ }^{4}$ dificultam uma análise mais minuciosa sobre aspectos de homofilia/heterofilia eletiva e indutiva. Vale ressaltar que o Facebook e outras plataformas não permitem a extração deste tipo de dado.

\footnotetext{
${ }^{4}$ Carecem de consentimento explícito da pessoa e para um fim definido. Ex.: revelam origem racial ou étnica, convicções religiosas ou filosóficas, opiniões políticas, filiação sindical, questões genéticas, biométricas e sobre a saúde ou a vida sexual de uma pessoa.
} 
Figura 6: Exemplo de comentários com relação direta e relação parcial a publicação de marco feliciano

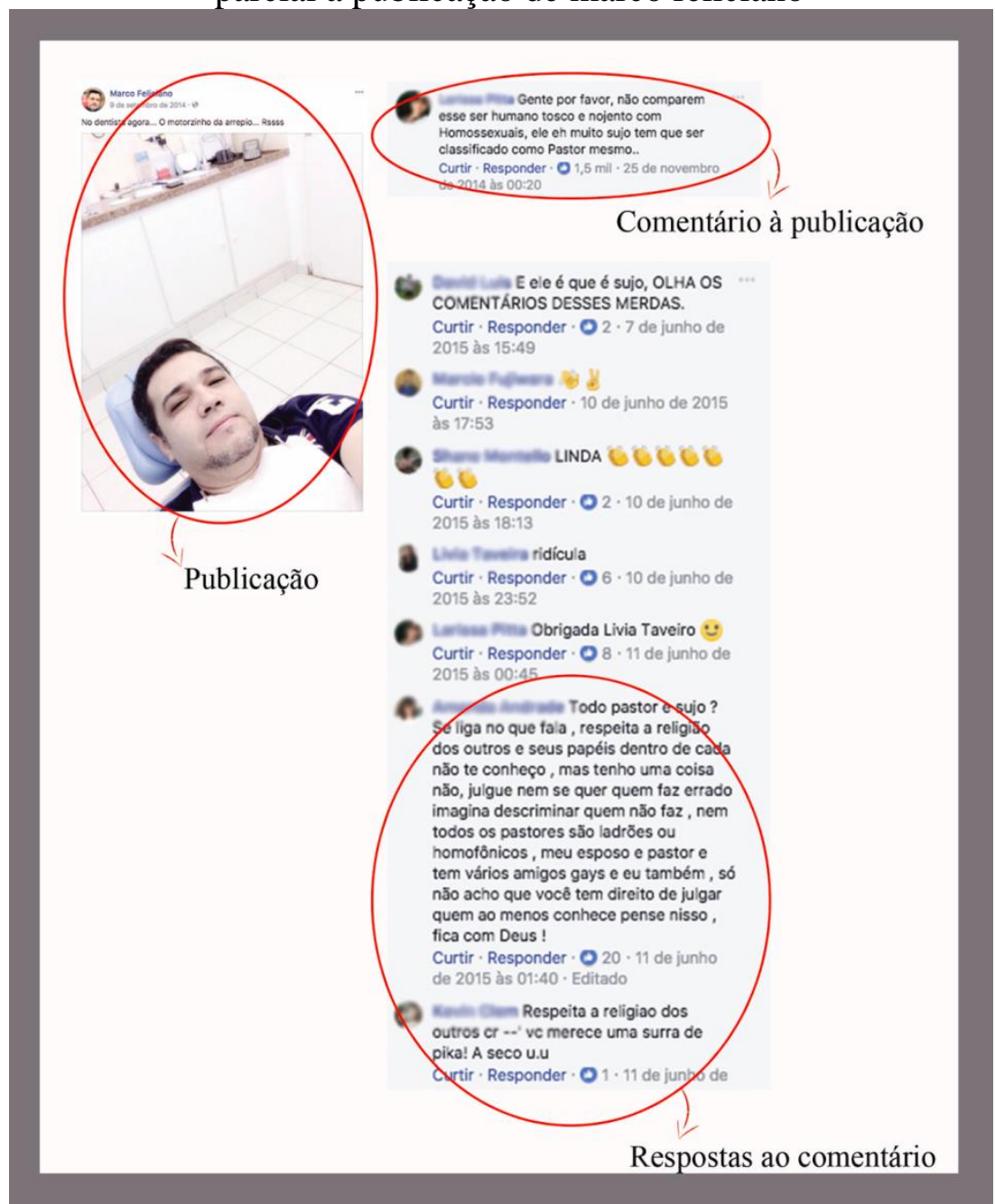

FONTE: O autor (2018)

No estudo também se identificou que a presença de Haters superou a de Trolls e Naysayers. Das interações analisadas, 97\% foram de interagentes-haters que manifestavam ódio de forma agressiva e direta. Os Haters promoveram todos os tipos de ódio abordados político partidário, racial, homofóbico, xenofóbico, sexista, etário, aporofóbico, intolerância religiosa, por aparência e contra pessoas portadoras de necessidades especiais. Os comentários proferidos por estes interagentes tinham uma desinibição tóxica (SULER, 2004), caracterizada por linguagem rude, críticas severas, raiva e ódio.

Os interagentes alcançaram o status de haters por dois motivos mais evidentes: (1) "Odiar por odiar, esse é o lema” (BREVES; SAMPAIO, 2014), não demonstrando nenhum embasamento que justifique a sua raiva, ou muitas vezes reproduzindo o discurso de ódio de outrem (parlamentar e/ou outro comentador) sem reflexão e análise dos fatos - "Larga de ser idiota gordo filho da puta, vai procurar seu pênis, se é que ainda tem. Lave a boca pra falar 
do Bolsomito!"; (2) reiterando um ódio fundado em argumentos históricos, religiosos, políticos e culturais que legitimam a manutenção do status quo em detrimento da dignidade de pessoa e outros direitos fundamentais das vítimas do ódio.

Gráfico 3 - Interagente-odiador

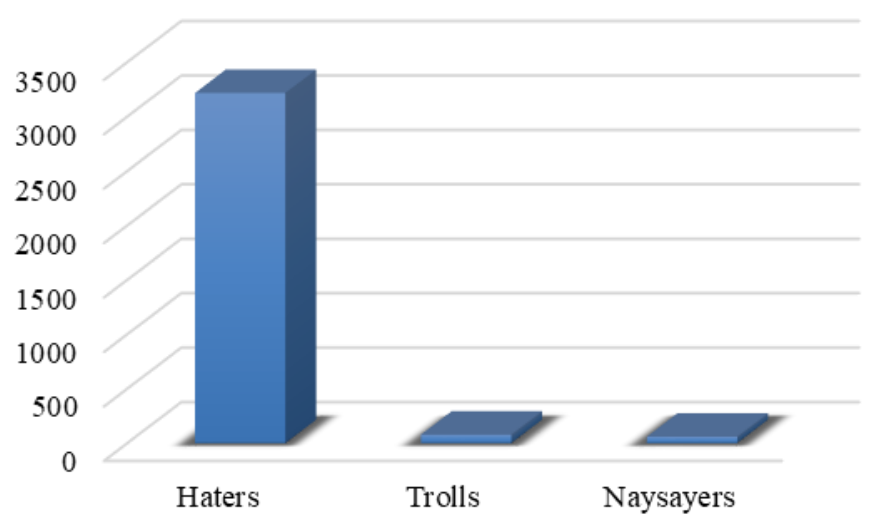

FONTE: O autor (2018)

Conforme gráfico 3, os Trolls não tiveram presença tão expressiva (2\%). A indisponibilidade do anonimato na plataforma pode ter inibido o comportamento amoral e narcisista destes interagentes. Os comentários identificados como troll carregam expressões jocosas e buscam desvirtuar o assunto em questão, atraindo a atenção para si próprios.

Os Naysayers (opositores) também não foram tão recorrentes, alcançando pouco mais de $1 \%$. Estes interagentes, por sua vez, demonstraram de forma clara sua oposição a quaisquer dos lados, reforçando um descrédito nas instituições políticas, nos brasileiros e nas ações de combate a corrupção.

As interações analisadas atestam como a "audiência do ódio" usou de discurso intolerante e incivil para autopromoção, defesa de bandeiras conservadoras e extremistas, além de um forte uso de campanha de desinformação, popularmente conhecidas como "Fake News". Outro ponto importante é o uso de preceitos religiosos, sobretudo o cristianismo, como justificativa para a segregação, violência e ódio.

\section{CONSIDERAÇÕES FINAIS}

Este estudo procurou abordar qual o tipo de interagente manifesta discurso de ódio contra grupos de características protegidas - negros, mulheres, imigrantes, gays, entre outros - 
no Facebook de políticos brasileiros e qual a relação entre a publicação e os comentários. Os resultados mostraram que interagentes haters, trolls e naysayers se reconhecem homofilicamente e passam a construir narrativas de discurso odiento quando fomentadas por seus administradores.

Nas páginas estudadas, o ódio e contra-ódio produzido e disseminado pelos interagentes manifestam animosidade para diferentes grupos de pessoas, além de serem usados como propaganda política. A maior parte das interações, de maneira explícita ou sofisticadamente, serviu para fortalecer as bandeiras políticas e religiosas dos parlamentares e diminuir a credibilidade de seus opositores. O conteúdo gerado pelos deputados construiu narrativas pautadas em espectros ideológicos, apelando para o esvaziamento das causas, comparando reivindicações de direitos das minorias com busca por privilégios.

Os interagentes, por sua vez, usaram do campo de comentários dessas postagens (muitas delas envoltas em desinformação, com partes fragmentadas e incompletas) para manifestar o ódio. A maioria dos interagentes-odiadores são haters e o estudo identificou a relação direta entre comentários e a postagem, prevalecendo um discurso de ódio homofílico. Neste sentido, os interagentes de pensamento comum, favoráveis aos parlamentares e suas convicções, demostraram ódio, repulsa e agressão aos demais comentadores, a figuras públicas de pensamento progressista e atacavam grupos minoritários, entre eles indígenas, negros, homossexuais; desrespeitavam as religiões distintas das de matriz cristã-judaica; e tratavam o imigrante como estrangeiro, despatriado.

Ressalta-se, no entanto, que este estudo tem limitações concentradas na coleta e tratamento dos dados, tendo em vista as políticas de dados do Facebook e as restrições do aplicativo Netvizz, sobretudo na extração do conteúdo audiovisual das postagens. Como possibilidades de trabalhos futuros, faz-se necessário um estudo pormenorizado sobre a Política de Dados e moderação de conteúdo usadas tanto pelo Facebook como por outras plataformas de Redes Sociais.

Outra limitação é o fato do discurso de ódio está em constante evolução linguística, o que torna o dicionário de palavras e expressões escolhido obsoleto. Novas palavras e expressões estão sendo constantemente criadas e disseminadas para manifestar indiferença, racismo, discriminação e violência às pessoas e grupos, o que aponta a necessidade de aprimorar a gestão de conteúdo de ódio, especialmente no que tange a representação e recuperação deste tipo de informação.

De toda maneira, os resultados aqui apresentados devem ser interpretados como uma aproximação da complexidade do problema, em vez de um exercício preciso e final. A 
proliferação de discurso odiento nas Redes Sociais Digitais, principalmente quando endossada por figuras publicas, é preocupante. Além de reforçar o binarismo social e aumentar a polarização, o discurso de ódio fragiliza o estado democrático de direito. Todos os atores envolvidos devem reconhecer com seriedade e urgência o quanto que interações odientas reforçam a cisão social e a violência e encontrar formas mais democráticas de fazer oposição política que não a intolerância e a incivilidade. 


\section{REFERENCIAS}

AWAN, I. Islamophobia on social media: a qualitative analysis of the Facebook's walls ofhate. International Journal of Cyber Criminology, 10(1), 1-20, 2016.

BLAYA, Catherine. Book Review: Online Hate and Harmful Content - Cross-National Perspectives. Acta Sociologica, [s.1.], v. 61, n. 4, p.461-463, 4 jun. 2018. SAGE Publications. http://dx.doi.org/10.1177/0001699318775184.

BREVES, B; SAMPAIO, V. Human Evil. [S.1.]: Mauad Editora Ltda, 2014.

BROWN, A. What is hate speech? Part 1: The myth of hate. Law and Philosophy, 36(4), 419-468, 2017.

COE, K., Kenski, K; RAINS, S. A. (2014). Online and uncivil? Patterns and determinants of incivility in newspaper website comments. Journal of Communication, 64(4), 658-679, 2014.

CITRON, D.K . Crimes de ódio no ciberespaço . Harvard University Press, 2014.

COHEN-ALMAGOR, Raphael. "Why Confronting the Internet's Dark Side?" Philosophia (United States) , 45(3): 919-29, 2017.

COMITÊ DA EUROPA. 2017. Disponível em: https://www.coe.int/en/web/octopus/blog//blogs/cyberhate-on-cyber-space-cyberbullying-a-new-phenomenon-of-violence-amongyouth. Acesso em: 22 de jan. de 2019.

DELGADO, R., STEFANCIC, J. Hate speech in cyberspace. Wake Forest L. Rev., 49, 319, 2014.

GAGLIARDONI, Iginio, et al. Countering Online Hate Speech. Paris: UNESCO, 2015.

HARDAKER, C. Trolling in asynchronous computer-mediated communication: from user discussions to academic definitions. Journal of Politeness Research, 6, 215-242, 2010. http://dx.doi.org/10.1515/JPLR.2010.011.

HUGLEY, Matthew W; DANIELS, Daniels. 2013. "Racist Comments at Online News Sites: A Methodological Dilemma for Discourse Analysis." Media, Culture and Society, 35(3): 332-47, 2013.

ISASI, Alex Cabo, JUANATEY, Ana García .El discurso del odio en las redes sociales: un estado de la cuestión. Ajuntament de Barcelona, 2016. Disponível em:

http://ajuntament.barcelona.cat/bcnvsodi/wp-content/uploads/2015/03/Informe_discurso-delodio_ES.pdf.

JAISHANKAR, K. Cyber hate: Antisocial networking in the Internet. International Journal of Cyber Criminology, 2(2), 16, 2008.

Klein, A. Slipping racism into the mainstream: a theory of information laundering.

Communication Theory, 22(4), 427-448, 2012. 
KOWALSKI, R. M.; MORGAN, C. A; LIMBER, S. P. Traditional bullying as a potential warning sign of cyberbullying. School Psychology International, 33(5), 505-519, 2012.

LAZARSFELD, P.et al. Freedom and control in modern society. 1954.

LOZARES, C.; VERD, J. M.; BARRANCO, O. El potencial analítico de las redes sociométricas y ego-centradas: una aplicación al estudio de la cohesión-integración de colectivos sociales. Empiria: Revista de metodología de ciencias sociales, (26), 35-62, 2013.

MC PHERSON, M.; SMITH-LOVIN , L.; COOK, J. M. Birds of a feather: Homophily in social networks. Annual review of sociology, 27(1), 415-444, 2001.

MOLLICA, K. A.; GRAY, B.; TREVINO, L. K. Racial homophily and its persistence in newcomers' social networks. Organization Science, 14(2), 123-136, 2003.

MOUW, T. Social capital and finding a job: do contacts matter? American sociological review, 868-898, 2003.

Neuendorf, K. A. The content analysis guidebook. Sage, 2016.

NIELSEN, L. B. Subtle, pervasive, harmful: racist and sexist remarks in public as hate speech. Journal of Social Issues, 58(2), 265-280, 2002.

PÉLLICO NETO, S.; BRENA, D. Inventário Florestal. v 1. Curitiba: editorado, 1997.

REBS, R. R.; ERNST, A. Haters e o discurso de ódio: entendendo a violência em sites de redes sociais. Diálogo das letras, 6(2), 24-44, 2017.

RECUERO, Raquel. Redes sociais na internet. Porto Alegre: Sulina, 2009. Disponível em: http://www.ichca.ufal.br/graduacao/biblioteconomia/v1/wp-

content/uploads/redessociaisnainternetrecuero.pdf.

ROSNER, L.; KRAMER, N. C. (2016). Verbal venting in the social web: Effects of anonymity and group norms on aggressive language use in online comments. Social Media+ Society, 2(3), 2016.

ROST, K., STAHEL, L; FREY, B. S. Digital social norm enforcement: Online firestorms in social media. PLoS one, 11(6), 2016.

SILVA, L. R. L.; BOTELHO-FRANSCISCO, R. E.; PONTES, V. R. A gestão do discurso de ódio nas plataformas de redes sociais digitais: um comparativo entre Facebook, Twitter e Youtube. Revista ibero-americana de ciência da informação, 12(2), 470-492, 2019.

SILVA, L. R. L.; SAMPAIO, R. C. Impeachment, facebook e discurso de ódio: a incivilidade e o desrespeito nas fanpages das senadoras da república. Esferas, 1(10), 2018.

TOKUNAGA, R. S. Following you home from school: A critical review and synthesis of research on cyberbullying victimization. Computers in human behavior, 26(3), 277-287, 2010 . 